\title{
Reseña
}

\section{Bioética Clínica. Toma de Decisiones. Final de la Vida. Legislación Internacional}

\section{Review}

Clinical Bioethics. Decision making. End of Life. International Legislation

\section{Resenha}

Bioética Clínica. Tomada de Decisão Fim da vida. Legislação Internacional

\section{Viviana Perracini ${ }^{1}$}

Como su título indica, esta obra se ocupa de la bioética clínica, que comprende los problemas relacionados con la ética de la asistencia y la toma de decisiones, cuestión relevante en los tiempos que corren en razón del gran avance científico y tecnológico, y al cambio de paradigma en la relación médico paciente. No obstante, el interés principal está dirigido a sistematizar todo lo atinente al final de la vida, incluyendo la donación y trasplante de órganos y tejidos.

Por lo tanto, el texto es de suma actualidad y responde a muchos de los interrogantes que estas cuestiones suscitan. Este libro está dirigido a estudiantes y profesionales relacionados con la salud (medicina, enfermería, psicología, asistencia social, derecho, entre otras). Comprende consideraciones éticas, médicas y legales con el rigor científico y técnico que ello requiere; sin embargo, está escrito en un lenguaje accesible, haciendo que las complejidades puedan ser entendidas con facilidad.

La importancia también está dada por la trayectoria de su autora. Dinah Magnante es abogada, incursionó en el mundo de la bioética en el año 2001, más precisamente con la defensa judicial de los derechos de un paciente en el final de la vida. Esto la motivó a cursar posteriormente una maestría en Ética Biomédica en el Instituto de Bioética de la Universidad Católica Argentina (2003-2004), obteniendo su título en el año 2009, con la tesis Tratamientos Proporcionados y Desproporcionados en el Estado Vegetativo Persistente, síntesis que fue publicada en Vida y Ética del mencionado Instituto (Ed. Educa, año 11, $\mathrm{n}^{\circ} 1$, junio de 2010). Por sus conocimientos y experiencia colaboró con la

\footnotetext{
${ }^{1}$ Abogada. Directora de la Sala de Derecho de la Salud, Colegio de Abogados de Córdoba, Argentina. E-mail: vivigp2008@hotmail.com
} 
sanción de la ley 26.742 en Argentina, llamada de muerte digna, e intervino en los casos más emblemáticos sobre solicitud de retiro o adecuación de tratamientos. Uno de esos casos es D.M.A. S/Declaración de Incapacidad, con sentencia del mayor tribunal argentino en el año 2015. Es de destacar, que recientemente, el Poder Legislativo de Córdoba la ha distinguido por su aporte en la sanción de la ley 26.742 y por la autoría del libro que estamos recensionando. Al mismo tiempo, tuvimos la oportunidad de que brindara una disertación en el Colegio de Abogados de Córdoba, evento que organizamos de forma conjunta, las Salas de Derecho de la Salud y de Bioética, en la que expuso de manera clara su estudio y profundizó en cuestiones de orden práctico.

El libro consta de una breve introducción en el que se presenta un resumen de los temas que serán tratados a lo largo de sus once capítulos, planteando a su vez, algunas cuestiones clave. En primer lugar se destaca el rol preminente de la dignidad de la persona humana en el campo de la bioética y el bioderecho, como asimismo la necesidad de aproximar algunos conocimientos respecto a la bioética. De tal manera que el primer capítulo está dedicado a delinear el concepto de la bioética, sus orígenes, los antecedentes históricos y el contexto en el cual se fue generando en su país de nacimiento - Estados Unidos -, y como se fue expandiendo a otros países. Con esta síntesis, nos brinda un panorama general sobre el desarrollo de esta disciplina. Entre la bibliografía mencionada se destaca la obra del profesor argentino José Alberto Mainetti, como así también la obra de los españoles Jorge Ferrer y Juan Carlos Álvarez, y Diego Gracia Guillén.

Con el título Final de la Vida se plantea aclarar la terminología involucrada en esta temática, la cual se utiliza de manera confusa y muchas veces errónea, como muerte digna o derecho a morir dignamente, con la que se hace alusión a diferentes situaciones y en países con legislaciones también distintas. Así es que el capítulo segundo está destinado a definir los conceptos de Eutanasia y Suicidio Asistido, los países o estados que lo permiten y los requisitos necesarios para acceder a dichas prácticas. La autora toma varios testimonios de personas que solicitaron la eutanasia o el suicidio asistido en situaciones muy especiales, que ante la prohibición legal en sus países, decidieron hacerlo de manera clandestina. Los casos están comentados de manera muy sobria, pero que logra el poder interpelarnos sobre nuestra propia muerte, dicho de otra manera, de cómo quisiéramos vivir hasta el final. 
Una vez esclarecida la primera cuestión, el capítulo tercero aborda el tema del encarnizamiento terapéutico u obstinación terapéutica, haciendo una síntesis sobre el concepto que ha sido elaborado, fundamentalmente, por la Iglesia Católica. Los factores causales y las consecuencias de la obstinación terapéutica que se exponen en el texto, son validados con el aporte de estudios realizados mediante la técnica de encuesta. Sus resultados ponen de relieve la necesidad de conocimientos de aspectos bioéticos y de los derechos de los pacientes por parte de los operadores de la salud. Además de aportar datos interesantes y reveladores, conforma un buen marco introductorio sobre lo que se desplegará en los próximos tres capítulos.

En otras palabras, es el punto de partida para los fines que la autora se propone, donde justamente, surge la pregunta fundamental: ¿Cómo tomar decisiones éticas en la práctica clínica? En otras palabras, se trata de cómo deberían actuar los profesionales de la salud en función de respetar la dignidad de la persona humana; esto puede resultar fácil de enunciar, pero difícil de concretar por las mismas razones expuestas al comienzo de esta reseña.

A los fines de cumplir con esos fines, en el capítulo cuarto, la autora presenta las metodologías o procedimientos para la toma de decisiones en la práctica clínica, herramientas que nos brinda la bioética. Introduce el tema con citas muy ilustrativas del cardiólogo y bioeticista español Reyes López, quien afirma que la ética es inherente a la práctica de una medicina clínica de calidad, y que así como en los juicios clínicos para establecer su diagnóstico y terapéutica, el clásico ojo clínico no es suficiente, para buscar la conducta éticamente más correcta no basta con el llamado olfato moral. Por lo tanto, dice el profesional, el juicio clínico y el juicio ético, son dos procesos que exigen prudencia y método, es decir, una forma sistemática de análisis (página 67).

Así es que nos encontramos con una síntesis muy lograda del Modelo de los Principios. El mismo se basa en la elaboración de cuatro principios: respeto de la autonomía, de beneficencia, de no maleficencia y el principio de justicia. Los mismos fueron sistematizados y desarrollados en el ya clásico libro Principles of Biomedical Ethics, de Beauchamps y Childress, publicado por primera vez en 1979 en Estados Unidos. Hay que hacer notar que se tomó la obra original en su versión española, dirigida por Diego Gracia Guillén, que corresponde a la cuarta edición de la obra escrita en lengua inglesa. 
A continuación ha sumado otros modelos complementarios, como el presentado por el mismo Diego Gracia Guillén, uno de los máximos exponentes de la bioética de habla española, que se ha llamado Principialismo jeraquizado. Y la propuesta del biotecista chileno Juan Pablo Beca Infante, que resulta muy interesante, por su claridad y practicidad (página 81).

Para concluir con los modelos, se agrega una teoría que aparece sumamente novedosa y que proviene de la Bioética Personalista, corriente de bioética que sostiene la Iglesia Católica, llamada el Principio de lo éticamente adecuado en el uso de los medios de conservación de la vida, propuesta que ha sido desarrollada por el italiano Maurizio Calipari. El marco teórico descripto es ilustrado con algunos casos clínicos reales, para finalizar con un breve análisis y conclusión.

El capítulo quinto está dedicado a detallar de manera práctica cómo evitar la obstinación terapéutica, decisiones que se toman como consecuencia del juicio clínico y juicio ético o bien, por el rechazo del paciente a tratamientos. Las mismas son circunscriptas de la siguiente manera: 1) sedación paliativa o terminal; 2) limitación o adecuación del esfuerzo terapêutico; 3) Rechazo de tratamento; y 4) suspensión de atención médica por fallecimiento. Asimismo, hace hincapié en la universalización de los cuidados paliativos, tema al que se refiere ofreciendo un panorama respecto a la situación actual, y a la necesidad de su implementación tanto en el ámbito público como privado.

Seguidamente pone la atención en el retiro, abstención o suspensión de nutrición e hidratación por vías artificiales en los pacientes que se encuentran estado vegetativo o en mínima conciencia. Como sabemos, es el tema que más controversias sigue generando, tanto en el plano internacional como en Argentina. Señala asimismo, la reticencia por parte de muchos profesionales al retiro de estas sustancias por el valor simbólico y cultural que tiene el hecho de alimentar e hidratar, a ello se suma la oposición que asumieron varios representantes de la Iglesia (página 122). No obstante, sostiene la autora, ese pensamiento no es unívoco, así pues, aporta información con documentación destacada de moralistas católicos, quienes con sólidos fundamentos, sostienen una opinión distinta. Estos datos ya habían sido volcados en su tesis final de la maestría en ética biomédica, mencionada al principio. Sabemos que algunos sectores muy conservadores, se han opuesto sistemáticamente a la sanción de leyes que legitimaran el retiro o abstención de 
estas sustancias, obstáculos que han sido difíciles de sortear a la hora de legislar en los países que lo han hecho.

El capítulo seis está destinado a describir los estadios crónicos de trastornos de la conciencia. Aclara que los diagnósticos y tratamientos han sido desarrollados con la colaboración del médico especialista en terapia intensiva y neurología, Ignacio J. Previgliano, actual director del Hospital General de Agudos Juan A. Fernández de la Ciudad de Buenos Aires. Es sumamente interesante que se haya ocupado de clarificar este tema teniendo en cuenta la confusión que a menudo se produce respecto a diferenciar el estado de coma, del estado vegetativo, del de mínima conciencia, del síndrome de enclaustramiento, y la muerte encefálica. En el mismo capítulo describe algunos de los antecedentes de personas en estado vegetativo que tuvieron repercusión en el mundo y que fueron resueltos en los estrados judiciales. Desde Karen Ann Quinlan (1975), caso que marcó un hito en la historia de la bioética, al de la italiana Eluana Englaro (2009).

En el capítulo séptimo se centrará en comentar la legislación y jurisprudencia argentina. Sin embargo, el análisis que realiza, con apoyatura en la doctrina de prestigiosos juristas de Argentina, por tratarse de derechos inherentes a todas las personas, trasciende las fronteras. En ese sentido, toma como referencia la Declaración Universal sobre Bioética y Derechos Humanos, de Unesco, aprobada en el año 2005, que determina la obligación de respetar la dignidad humana, los derechos humanos y las libertades fundamentales.

Comienza esta sección con el tratamiento del Consentimiento Informado, para referirse primeramente a sus orígenes en Estados Unidos, y cómo la doctrina del consentimiento informado se fue incorporando a la legislación Argentina. Con la sanción de la ley 26.529 en el año 2009, conocida como Ley de Derechos del Paciente, se produce la expresión concreta del proceso del consentimiento informado, que estableció la obligación de respetar la autonomía de la voluntad en cuanto a "aceptar o rechazar determinadas terapias o procedimientos médicos o biológicos, con o sin expresión de causa”. Esta ley debió ser modificada en el año 2012 por la ley 26.742, llamada también ley de muerte digna, para poder cumplir con los requerimientos de pacientes y familiares, con la necesidad de determinar los tratamientos que se podían retirar o no instaurar, entre ellos, la nutrición e hidratación. En el año 2015 se sancionó el nuevo Código Civil y Comercial, que incorporó algunos artículos de la normativa mencionada, introduciendo un tratamiento 
especial en cuanto a los derechos de los menores de 18 años para la toma de decisiones referentes a su salud.

En el mismo capítulo aborda el concepto y el alcance de información que debe darse y a quiénes, como así también las diferencias entre capacidad y competencia o aptitud para dar el consentimiento informado, y cómo determinar la competencia para participar del C.I. El último apartado corresponde a las Directivas Anticipadas, y al final encontramos dos anexos que sirven como modelo, uno para la Adecuación de Tratamientos, y otro para las Directivas Anticipadas.

En el capítulo octavo, antes que todo, describe someramente los casos emblemáticos que dieron lugar a la sanción de la llamada ley de muerte digna en Argentina, para luego dedicarse al caso D.M.A. S/Declaración de Incapacidad, resuelto por la Corte Suprema de Justicia de la Nación del país. Dinah Magnante - como dijimos fue una de las profesionales que intervino en el caso-, hace un análisis del fallo, destacando la importancia de la resolución en el sentido que legitimó el reclamo de los familiares del paciente para el retiro de soporte vital, quien desde hacía 20 años y de acuerdo a las últimas pericias, se encontraba en estado de mínima conciencia en su variante minus. En ese orden de ideas, remarca los aspectos positivos de la sentencia en cuanto a que ratifica la plena vigencia de la normativa del país, cuyo objetivo principal es evitar la judicialización de los casos. No obstante, en su crítica al fallo, pone de manifiesto que la Corte ha hecho una interpretación restrictiva del texto legal. Así pues, agrega varios aspectos bioéticos que la decisión judicial no ha tenido en cuenta a la hora de decidir. Sus apreciaciones son sumamente importantes puesto que ayudan a interpretar con mayor claridad y profundidad la normativa vigente, lo que constituye un gran aporte a los fines prácticos.

Seguidamente, narra una serie de casos que se resolvieron con posterioridad a la sanción de la ley, manifestando que su aplicación resulta muchas veces dificultosa. Se trata de situaciones, en las que ha debido intervenir, ante la reticencia por parte de profesionales médicos, abogados e instituciones de salud. A medida que desarrolla cada uno de los casos, se van esclareciendo muchas cuestiones o dudas respecto a aspectos médicos, éticos y legales.

El capítulo noveno, brinda un panorama de la legislación internacional referida a garantizar los derechos al final de la vida de los pacientes. Analiza la normativa vigente de varios países de América Latina - Perú, México, Uruguay, Brasil, Paraguay, Chile y 
Ecuador -, la de Estados Unidos, y algunos países de Europa - España, Reino Unido, Francia, Italia y Alemania -, y de la India en el continente asiático. Se trata de una tarea encomiable por parte de la autora, quien ha tomando como base para su investigación los textos legales de cada país al que se refiere. Es cierto que para quienes no tienen el hábito de leer legislación podría resultar un poco árido, sin embargo, la capacidad de síntesis de la autora, sumado a sus comentarios, hacen que su lectura resulte amena.

El conocimiento del derecho comparado además de enriquecernos, exhorta a la elaboración y sanción de leyes en países donde no existe un marco legal que garantice derechos de los pacientes y otorguen, a su vez, seguridad jurídica a los médicos. Y en caso que los hubiere, para ampliarlos y mejorarlos.

No obstante, la autora destaca, que no solo es importante la sanción de leyes, sino la necesidad de profundizar el conocimiento para aplicarlas correctamente. Asimismo, afirma que estos temas afectan en la mayor parte de los países, tanto a profesionales de la salud, como a familiares y operadores de la justicia (página 211).

El capítulo décimo se ocupa de la relación médico paciente, y cómo comunicar malas noticias. Además de los aspectos relevantes de la comunicación, nos encontramos con un modelo o protocolo para dar malas noticias. Solo se trata de proporcionar una guía, puesto que el proceso de comunicación por parte de los profesionales de la salud es muy complejo que, además del saber teórico, requiere de un buen entrenamiento.

El libro finaliza con el capítulo undécimo Donación y trasplante de órganos y tejidos. En su introducción se destaca la necesidad de incentivar la donación y la preparación de los equipos de salud. Através de una breve encuesta se explican los aspectos más relevantes de la normativa legal argentina, con la última modificación realizada con la sanción de la ley 27.447 en el año 2018. Entre sus modificaciones, incorpora la donación renal cruzada.

El último punto es muy novedoso al plantear los nuevos desafíos de la región en donación y trasplantes de órganos, se trata de la donación en asistolia (o por parada cardíaca). Esta modalidad se ha incorporado desde hace muchos años en el plano internacional, especialmente en España, pero en nuestra región, hasta el momento, no se ha puesto en práctica puesto que genera algunas controversias.

En función de aclarar estas cuestiones, se exponen los aspectos médicos y éticos, para luego preguntarse si es posible en Argentina la donación en asistolia. En este punto 
se plantea si el marco legal del país es suficiente para su implementación, y para ello realiza un interesante análisis de la legislación argentina para dar su conclusión.

En mi opinión, se trata de un libro recomendable y de gran interés por tratar aspectos diversos sobre la práctica clínica, que se encuentran lógicamente estructurados. Entre los aportes principales se puede resaltar la base documental, además de la capacidad a de la autora para sintetizar y destacar lo más importante en cada cuestión. La claridad expositiva de sus análisis junto al desarrollo de casos concretos facilita enormemente la tarea de la comprensión por parte de los lectores. Esto da prueba de su competencia y habilidad, que deriva evidentemente de extensas lecturas, pero especialmente de su destreza en las lides de esa "trinchera" que constituyen los ámbitos judiciales, de la medicina y fundamentalmente del contacto directo con el sufrimiento de las personas. Sin duda alguna, el presente libro se configura como un material de consulta y de formación.

\section{Referência}

Magnante D. Bioética Clínica. Toma de Decisiones. Final de la Vida. Legislación Internacional. Ciudad Autónoma de Buenos Aires: Corpus Libros Médicos y Científicos; 2019. 248 p. ISBN 978-987-1860-53-1. 